\title{
Analysis of Optical Attenuation from Measured Visibility Data in Islamabad, Pakistan
}

\author{
RAHIMDAD KHAN*, RAHMAN WALI KHATTAK*, MUHAMMAD SAEED KHAN**†, AND \\ MUHAMMAD TAHIR MUSHTAQ***
}

RECEIVED ON 07.10.2016 ACCEPTED ON 29.05.2017

\begin{abstract}
FSOL (Free-Space Optical Links) are becoming very popular due to the inherent advantages of high data rates, rapid deployment, portability, cost effective and immunity to electromagnetic interference. FSOL is a line-of-sight technology that uses a modulated beam of light to transmit and receive the data of multiple of Giga Bit per second. FSOL uses the free space or atmosphere as a communication channel. Optical signal launched at transmitter end, travels through the atmosphere and reaches to the receiver, is severely affected by the local atmospheric conditions. Atmosphere contains different atmospheric particulates like fog, rain, snow, smog, clouds and haze. These atmospheric particulates, particularly fog, effect the propagation of optical signal passing through the atmosphere and cause significant amount of optical attenuation. In order to deploy FSO system, a detailed analysis of local weather condition is much more important. Here, we present the measured visibility data for analysis of optical attenuation. Visibility data was measured at COMSATS Institute of Information Technology from 2009-2012. Percentage CDF (Cumulative Distribution Function) is used to find out the detailed insight about the optical attenuation of FSOL. Yearly based CDFs is compared with each other which clearly suggest that almost $99 \%$ of time optical attenuation remains within the range of $2 \mathrm{~dB} / \mathrm{km}$.
\end{abstract}

Key Words: Free Space Optical Communication, Optical Wireless Communication, Visibility, Link Range, Link Margin, Optical Attenuation, Fog.

\section{INTRODUCTION}

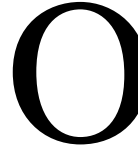
ver the last two decades, higher data rates demands are significantly increasing day-byday [1]. Fiber optics can provide higher data rates to meet the needs of end-user. Although fiber optics could meet the requirements of capacity hungry communication application but it is expensive and take a long time to install a fiber network [2]. Fiber optic is mainly used as the backbone of communicating network. This creates bottle neck between main network and user end or the "last-mile" problem. FSOL can be used to bridgeup the "last mile" access problem. FSOL is an emerging technology which has the ability to tackle capacity hungry

†Corresponding Author (E-Mail: msaeedbaloch@gmail.com)

* Department of Electrical Engineering, COMSATS Institute of Information Technology, Wah Cantt.

** Department of Electrical Engineering, University College of Engineering Science \& Technology, Leads University, Lahore.

*** School of System and Technology, University of Management \& Technology, Lahore.

This is an open access article published by Mehran University Research Journal of Engineering and Technology, Jamshoro under the CC by 4.0 International License. 
applications, particularly in LAN (Local Area Networks) and MAN (Metropolitan Area Networks) [3-4]. FSOL is used to connect the existing MAN to existing core networks and also used to cope with the last mile access problem [5-6]. FSOL not only provides high data rates but it is very easy to install and consist of very compact equipment of light weight [7-8]. The advantages of rapid deployment, portability and high data rate make FSOL as a potential alternative to radio frequency links. FSOL have been in use for different nomadic communication application for civil and military [9-12].

FSOL use the same technology as that of fiber optics. The major difference between FSOL and fiber is of medium. Fiber optics use guided medium for transmission whereas FSOLuse atmosphere as propagation medium, therefore, light propagation faces different challenges while propagating through the atmosphere. Different weather conditions strongly affect the propagation of optical signal and degrade performance of the FSO communication system. The atmospheric conditions affect the reliability and availability of FSO Links. Atmosphere contains fog, rain, smoke, smog and other atmospheric particulates which often alter the propagation of signal through it [13-14]. Out of all these atmospheric conditions, fog is the major challenge for FSO communication links which sometime almost reduce the availability to $0 \%$ [2]. Fog in the atmosphere causes to reduce the visibility. Several models are used to estimate optical attenuation through fog using visibility as an input parameter, like Kim and Kruse model.In this paper we presented the detailed analysis of visibility and estimated optical attenuation from the real time measured data of visibility of four years. The measurements were carried out from September 2009 to December 2012. Khan et. al. [15], only four fog events were selected to estimate optical attenuation using Kim, Kruse and Al Naboulsi models while here we presented the conclusive analysis of 4 years data of visibility. Three wave lengths $10 \mu \mathrm{m}, 830$ and 1550 $\mathrm{nm}$ are used to estimate specific optical attenuation. Descriptive statistics is presented to show the statistics of attenuation during the period of measurement campaign.

\section{KRUSE AND KIM MODEL}

Kruse and Kim model are the wavelength dependent model used to estimate specific optical attenuation from visibility data. Visibility can be defined as the distance through which $5 \%$ or $2 \%$ of $550 \mathrm{~nm}$ collimated light is attenuated of an original power [16]. The attenuated power is measured in $\mathrm{dB} / \mathrm{km}$ while visibility is used in $\mathrm{Km}$. For 5\% threshold Kim and Kruse model is [17-18].

$\Omega_{\text {spec }}=\frac{13}{V(k m)}\left(\frac{\lambda}{\lambda_{0}}\right)^{-q}$

Where in above $\Omega_{\text {spec }}$ is specific optical attenuation, $\lambda$ is wave length of optical signal in $\mathrm{nm}, \lambda_{\mathrm{o}}$ is reference wave length which is $550 \mathrm{~nm}$ and $\mathrm{q}$ is the size distribution of the scattering particles. The expression for estimation of optical attenuation is same for both Kim and Kruse model but main difference is the parameter q that both models used for calculation. The value of $q$ for Kruse model is given as:

$q=\left\{\begin{array}{c}1.6 \text { if } \mathrm{V}>50 \mathrm{~km} \\ 1.3 \text { if } 6 \mathrm{~km}<\mathrm{V}<50 \mathrm{~km} \\ 0.585 \mathrm{~V}^{1 / 3} \text { if } \mathrm{V}<6 \mathrm{~km}\end{array}\right.$

Kruse model cannot precisely estimate specific attenuation when visibility is less than $1 \mathrm{~km}$ and it estimates less optical attenuation for longer wavelengths.

On the other hand Kim presented new definition of $\mathrm{q}$ parameter when visibility is less than $500 \mathrm{~m}$. This makes higher wavelength advantage less for lower visibility values. According to Kim values of $\mathrm{q}$ are as under:

$\mathrm{q}=\left\{\begin{array}{c}1.3 \text { if } 6 \mathrm{~km}<\mathrm{V}<50 \mathrm{~km} \\ 0.16 \mathrm{~V}+0.34 \text { if } 1 \mathrm{~km}<\mathrm{V}<6 \mathrm{~km} \\ 0 \text { if } \mathrm{V}<0.5 \mathrm{~km}\end{array}\right.$ 


\section{EXPERIMENTALSETUP}

Experimental campaign was carried out Department of Meteorological, COMSATS Institute of Information Technology, Islamabad, Pakistan, from $1^{\text {st }}$ September 2009 to $30^{\text {th }}$ December 2012. Islamabad is located at $33.43^{\circ} \mathrm{N}$ and $73.04^{\circ} \mathrm{S}$; at the edge of Pothohar plateau. Its height from sea level is $1663 \mathrm{ft}$. It generally has a warm temperature climate with dry winter and hot summer. Over the course of year temperature changes between $1-43^{\circ} \mathrm{C}$.

Experimental setup consists of Vaisala FS 11 visibility measuring sensor to measure visibility. The measurement frequency was 6 values in one hour, i.e. one value after 10 minutes. As FS11 uses 5\% visibility threshold so all the calculations were done using $5 \%$ formula for specific attenuation.Temperature, Relative humidity, average wind speed, few point and atmospheric pressure were measured by the Vaisala automatic weather station. These weather parameters are plotted along with visibility and specific attenuation to analyze the variation in the visibility and specific optical attenuation due to these weather parameters. Empirical models were applied to estimate specific optical attenuation at the wavelengths of 830 , 1550 and $10,000 \mathrm{~nm}$.

\section{RESULTS AND SIMULATIONS}

Three long-term and real time measured data of visibility allows us to estimate specific optical attenuation using Kim and Kruse models. The analysis helps us to analyze the availability of an FSO link for one year as well as for the whole period and provide us a detailed insight about the channel conditions. As per best of author knowledge this is the $1^{\text {st }}$ attempt to provide the feasibility analysis for the deployment of FSOL in the region of Islamabad and surroundings.

\subsection{Simulation Results of Visibility from September 2009 to 31 December 2009}

Fig. 1 provides the time series plot of recorded visibility for the last four months of 2009. The maximum visibility was $48.16 \mathrm{~km}$ while the minimum was $0.96 \mathrm{~km}$ recorded.

The attenuation are estimated for the year 2009 by Kim and Kruse models by the real time visibility data using $830 \mathrm{~nm}, 1550 \mathrm{~nm}$ and $10 \mu \mathrm{m}$ wavelengths. Figs. $2-3$ presents the time series of estimated specific optical attenuation by Kruse and Kim model at a minute scale for 2009 respectively.

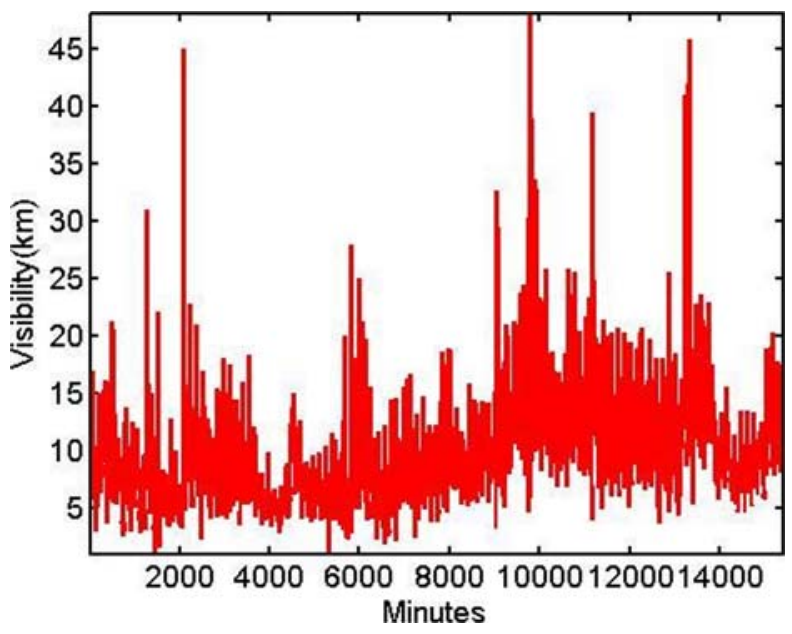

FIG. 1. TIME SERIES PLOT OF VISIBILITY FOR LAST FOUR MONTHS OF 2009

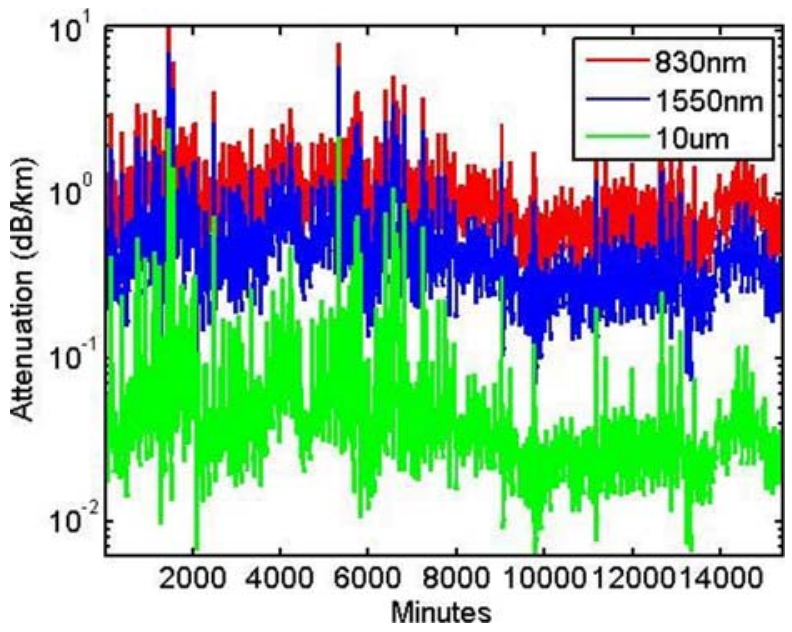

FIG. 2. TIME SERIES PLOT OF ESTIMATED SPECIFIC OPTICAL ATTENUATION BY KRUSE MODEL FOR 2009

Mehran University Research Journal of Engineering \& Technology, Volume 37, No. 2, April, 2018 [p-ISSN: 0254-7821, e-ISSN: 2413-7219] 


\subsection{Simulation Results of Visibility for the Year 2010}

Fig. 4 provides the time series plot of recorded visibility for the year of 2010.The maximum recorded visibility was $75 \mathrm{~km}$ while the minimum recorded visibility is $0.10 \mathrm{~km}$ recorded.

Figs. 5-6 presents the time series of estimated specific optical attenuation by Kruse and Kim model at a minute scale for the year 2010, respectively.

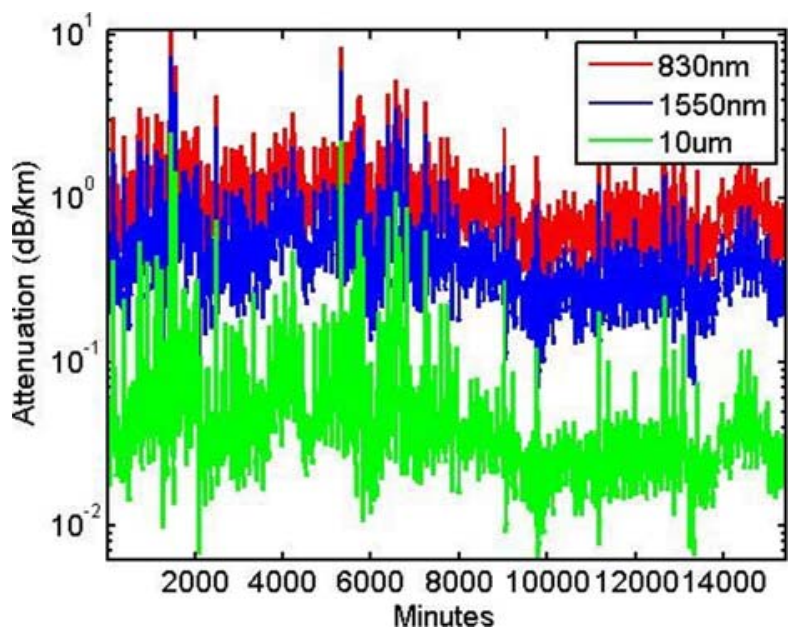

FIG. 3. TIME SERIES PLOT OF ESTIMATED SPECIFIC OPTICAL ATTENUATION BY KIM MODEL FOR 2009

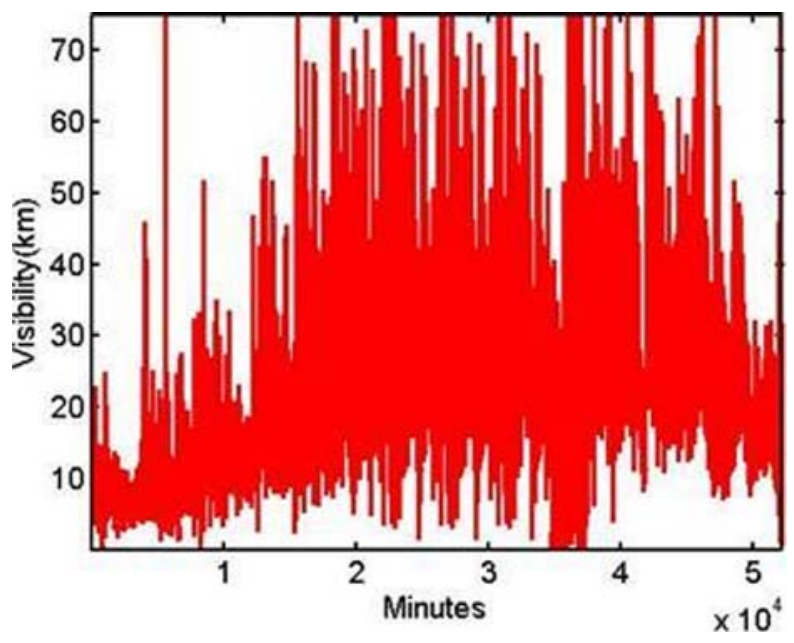

FIG. 4. TIME SERIES PLOT OF VISIBILITY FOR YEAR OF 2010

\subsection{Simulation Results of Visibility for the Year 2011}

Fig. 7 provides the time series plot of recorded visibility for the year 2011. The maximum visibility was $75 \mathrm{~km}$ while the minimum visibility was $0.13 \mathrm{~km}$ recorded.

Figs. 8-9 presents the time series of estimated specific optical attenuation by Kruse and Kim model at a minute scale for the year 2011.

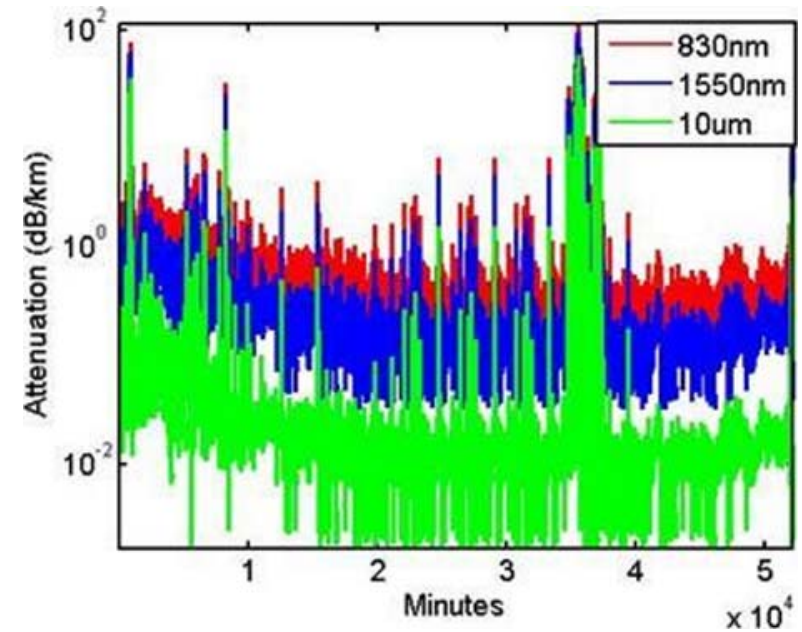

FIG. 5. TIME SERIES PLOT OF ESTIMATED SPECIFIC OPTICAL ATTENUATION BY KRUSE MODEL FOR THE YEAR 2010

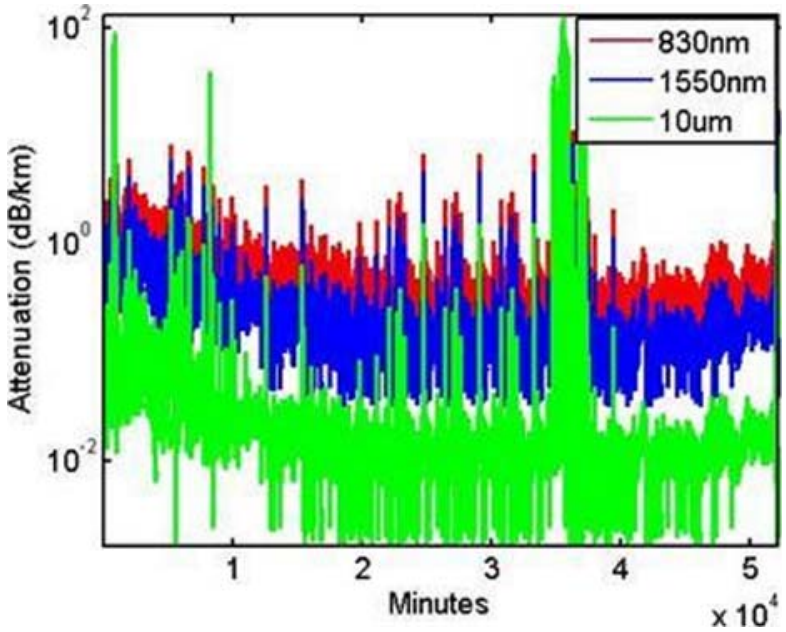

FIG. 6. TIME SERIES PLOT OF ESTIMATED SPECIFIC OPTICAL ATTENUATION BY KIM MODEL FOR THE YEAR 2010

Mehran University Research Journal of Engineering \& Technology, Volume 37, No. 2, April, 2018 [p-ISSN: 0254-7821, e-ISSN: 2413-7219] 


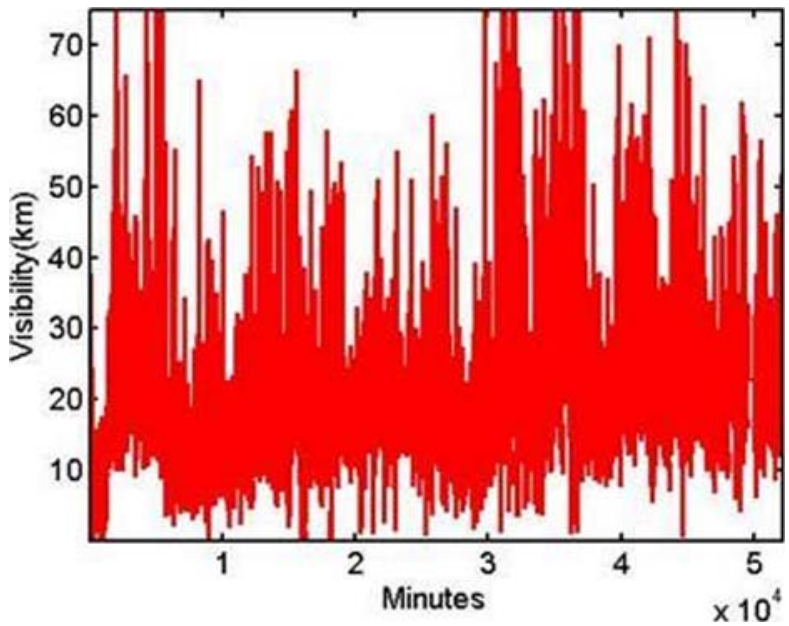

FIG. 7. TIME SERIES PLOT OF VISIBILITY FOR YEAR OF 2011

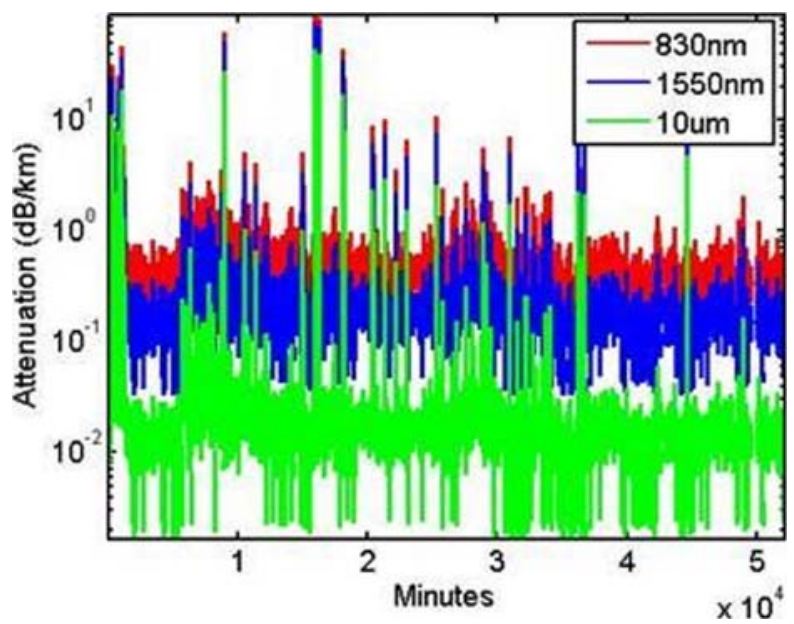

FIG. 8. TIME SERIES PLOT OF ESTIMATED SPECIFIC OPTICAL ATTENUATION BY KRUSE MODEL FOR THE YEAR 2011

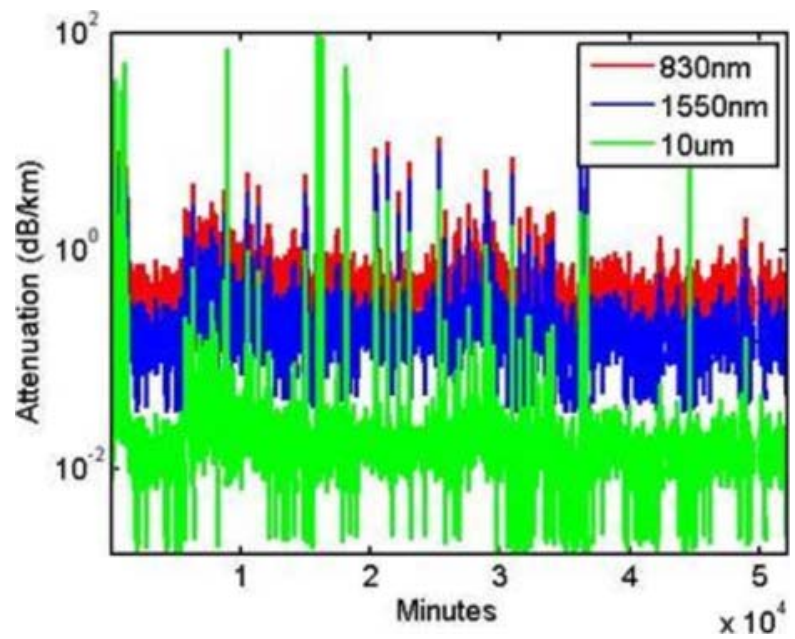

FIG. 9. TIME SERIES PLOT OF ESTIMATED SPECIFIC OPTICAL ATTENUATION BY KIM MODEL FOR THE YEAR 2011

\subsection{Simulation Results of Visibility for the Year 2012}

Fig. 10 is the plot of recorded visibility for 2012. The visibility in $\mathrm{km}$ is at minute scale. The maximum visibility was $75 \mathrm{~km}$ while the minimum was nearly zero km recorded.

Figs. 11-12 presents the time series of estimated specific optical attenuation at a minute scale for the year 2012. This clearly indicates when the visibility increases the optical attenuation decreases. For Kruse model $830 \mathrm{~nm}$ wave length signal attenuate maximum as compared to 10 $\mu \mathrm{m}$ and $1550 \mathrm{~nm}$. While for Kruse model optical attenuation is maximum at $10 \mu \mathrm{m}$

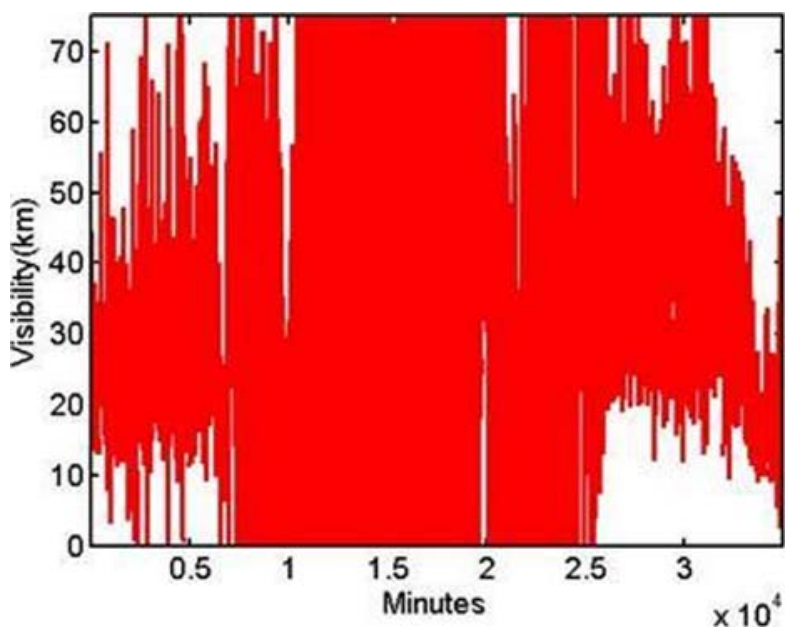

FIG. 10. TIME SERIES PLOT OF VISIBILITY FOR YEAR OF 2012

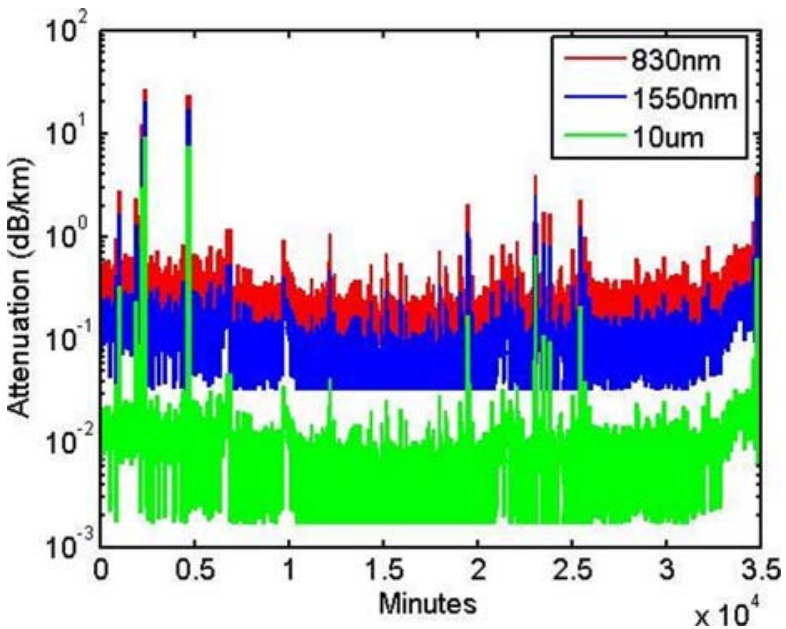

FIG. 11. TIME SERIES PLOT OF ESTIMATED SPECIFIC OPTICAL ATTENUATION BY KRUSE MODEL FOR THE YEAR 2012

Mehran University Research Journal of Engineering \& Technology, Volume 37, No. 2, April, 2018 [p-ISSN: 0254-7821, e-ISSN: 2413-7219] 


\section{COMBINED SIMULATION RESULTS OF VISIBILITY DATA}

Fig. 13 shows the time series plot of visibility from 1st September 2009 to 31st December 2012. The maximum measured visibility during the whole measurement campaign is $75 \mathrm{~km}$ while minimum is almost zero km during the dense fog event of 2012.

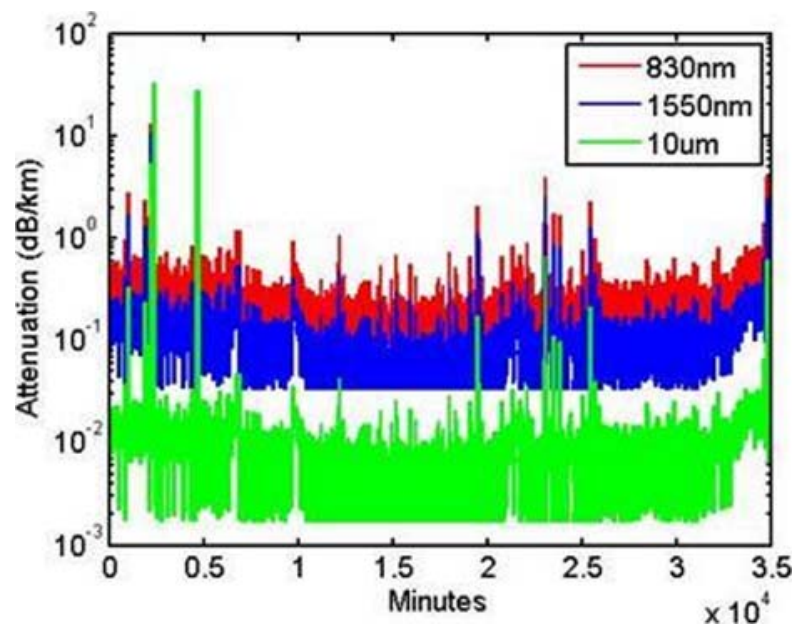

FIG. 12. TIME SERIES PLOT OF ESTIMATED SPECIFIC OPTICAL ATTENUATION BYKIM MODEL FOR THE YEAR 2012

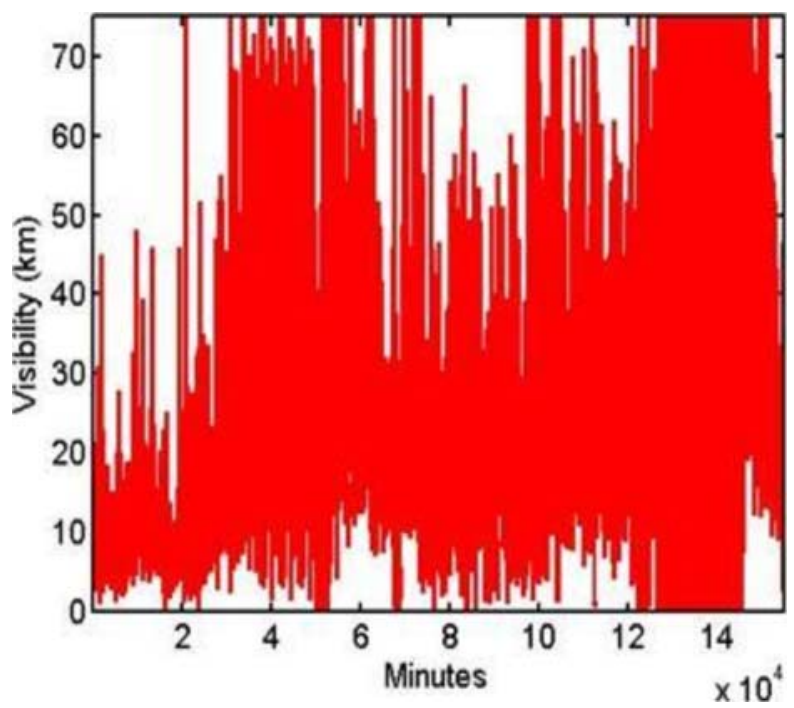

FIG. 13. TIME SERIES PLOT OF VISIBILITY FOR 3 YEARS AND 4 MONTHS
Figs. 14-15 presents the time series of estimated specific optical attenuation by Kruse and Kim model at a minute scale for the complete set of data.

The analysis show that over $70 \%$ of the time attenuation remain at the range of $2-5 \mathrm{~dB} / \mathrm{km}$ and approaches to 120 $\mathrm{dB} / \mathrm{km}$ at $1550 \mathrm{~nm}$ wave length using Kruse model while in case of Kim model $120 \mathrm{~dB} / \mathrm{km}$ at the wave length of $10 \mu \mathrm{m}$.

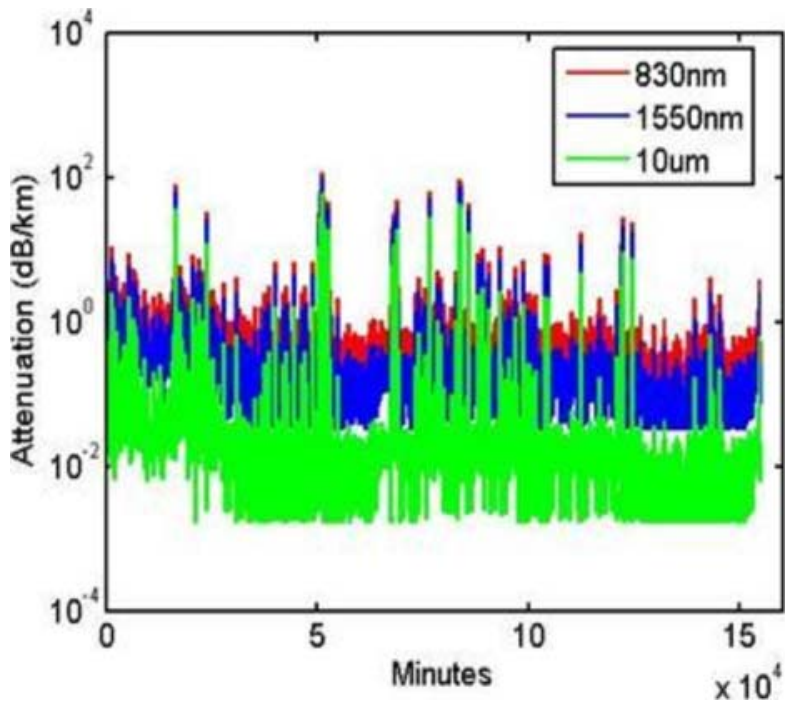

FIG. 14. TIME SERIES PLOT OF ESTIMATED SPECIFIC OPTICAL ATTENUATION BY KRUSE MODEL FOR 3 YEAR AND 4 MONTHS

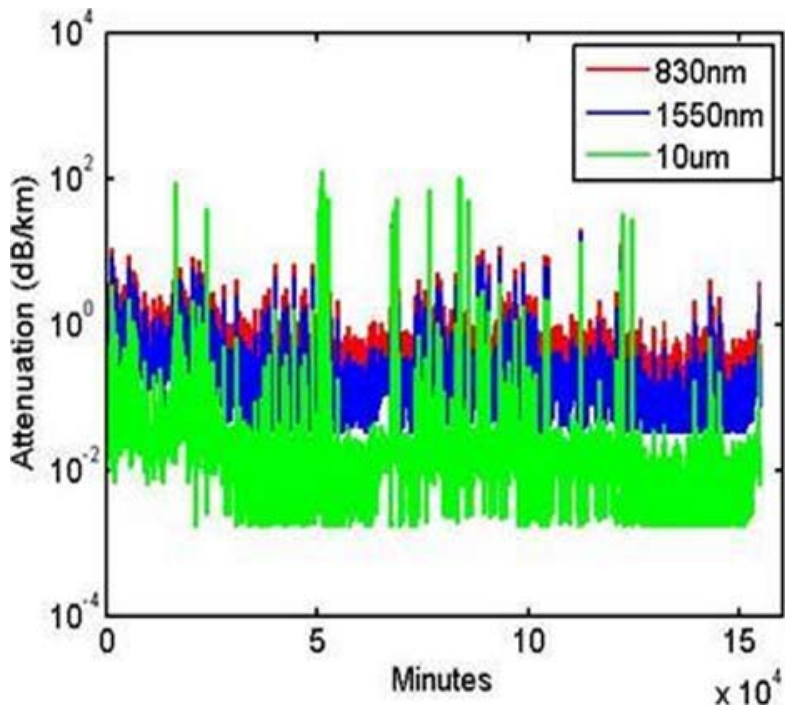

FIG. 15. TIME SERIES PLOT OF ESTIMATED SPECIFIC OPTICAL ATTENUATION BY KIM MODEL FOR 3 YEARS AND 4 MONTHS

Mehran University Research Journal of Engineering \& Technology, Volume 37, No. 2, April, 2018 [p-ISSN: 0254-7821, e-ISSN: 2413-7219] 


\section{COMBINED DESCRIPTIVE DATA STATISTICS OFVISIBILITY}

Table 1 shows the statistical analysis of the observed visibility data in kilometers. The data is classified according to yearly order and then the whole data is combined to calculate statistical parameters. It is evident from the statistics that in year 2009 the mean visibility is much less as compared to the subsequent years because the campaign started in the last quarter of the year in winter season, similarly this is also the reason that we see a small median value for year 2009 as compared to the rest of the years. The mode of a set of data is the value which occurs most frequently. Here the mode value for year 2011 is of much interest because it show a steep decrease that is only $22.71 \mathrm{~km}$ in contrast with the $75 \mathrm{~km}$ value for other years except 2009 which is a different case on account of the duration and timing of the observations.

The decrease in mode indicates that in this year there might have been any abnormal weather changes which led to decreased visibility, the standard deviation for this year also strengthens this argument because it is the lowest among all the three full years' data. This shows that the entire set of data for year 2011 lies close to the mean value. The most wide spread out data over a large range of values is of year 2012 with the highest standard deviation of 17.971. The highest value of standard deviation for the year 2012 also indicates the same fact that in 2012 the data points were spread out on a wide range. From range it can be concluded from the whole data that at most the visibility can reach up to $75 \mathrm{~km}$ and the least it can get is almost equal to zero.

\subsection{Descriptive Data Statistics of Optical Attenuation}

Table 2 shows the statistical analysis of the estimated optical attenuation for the year 2009. Optical attenuation is estimated by Kruse and Kim models for $830 \mathrm{~nm}, 1550$ $\mathrm{nm}$ and $10 \mu \mathrm{m}$ wave lengths.

According to both models the mean, median and mode of attenuation is approximately same for all the frequencies, this largely due to the fact that corresponding visibility data has a very small standard deviation. This further led to a small standard deviation in the estimated optical attenuation.

TABLE 1. DESCRIPTIVE STATISTICS OF VISIBILITY DATA

\begin{tabular}{|c|c|c|c|c|c|}
\hline Years & 2009 & 2010 & 2011 & 2012 & Combined Data \\
\hline Mean & 10.50 & 23.31 & 21.95 & 39.41 & 25.21 \\
\hline Median & 9.679 & 22.29 & 20.51 & 36.63 & 22.20 \\
\hline Mode & 6.05 & 75.00 & 22.71 & 75.00 & 75.00 \\
\hline Standard Deviation & 4.655 & 12.54 & 10.06 & 17.97 & 15.30 \\
\hline Range & 47.19 & 74.90 & 74.87 & 75.00 & 75.00 \\
\hline
\end{tabular}

TABLE 2. DESCRIPTIVE STATISTICS OF ESTIMATED OPTICAL ATTENUATION FOR 2009

\begin{tabular}{|c|c|c|c|c|c|c|}
\hline \multicolumn{4}{|c|}{ Kruse Model } & \multicolumn{3}{c|}{ Kim Model } \\
\hline & $830 \mathrm{~nm}$ & $1550 \mathrm{~nm}$ & $10 \mu \mathrm{m}$ & $830 \mathrm{~nm}$ & $1550 \mathrm{~nm}$ & $10 \mu \mathrm{m}$ \\
\hline Mean & 0.88 & 0.41 & 0.043 & 0.88 & 0.41 & 0.04 \\
\hline Median & 0.78 & 0.34 & 0.030 & 0.78 & 0.34 & 0.03 \\
\hline Mode & 1.26 & 0.56 & 0.05 & 1.26 & 0.5 & 0.05 \\
\hline Standard Deviation & 0.47 & 0.278 & 0.068 & 0.47 & 0.28 & 0.07 \\
\hline Range & 10.49 & 7.35 & 2.52 & 11 & 8.29 & 3.52 \\
\hline
\end{tabular}

Mehran University Research Journal of Engineering \& Technology, Volume 37, No. 2, April, 2018 [p-ISSN: 0254-7821, e-ISSN: 2413-7219] 
Table 3 shows the descriptive statistics of optical attenuation by both Kim and Kruse models for $830 \mathrm{~nm}$, $1550 \mathrm{~nm}$ and $10 \mu \mathrm{m}$ wave lengths in the year 2010. In the attenuation data of year 2010 it has been found that both the Kruse and Kim model median and mode values for all the three wavelengths are same but there is a slight disagreement among these models regarding the mean attenuation, more specifically for the $10 \mu \mathrm{m}$ wavelength, that is 0.116 and $0.278 \mathrm{~dB} / \mathrm{km}$ for Kruse and Kim model respectively. The standard deviation for $10 \mu \mathrm{m}$ in both the models is quite unusual because in Kruse model it has the small standard deviation of 1.325 whereas in Kim model we have much greater value of 3.593. Tables 3-6 show the descriptive statistics of optical attenuation by both Kim and Kruse models for $830 \mathrm{~nm}, 1550 \mathrm{~nm}$ and $10 \mu \mathrm{m}$ wave lengths in the year 2011,2012 and for combined data set respectively.

TABLE 3. DESCRIPTIVE STATISTICS OF ESTIMATED OPTICAL ATTENUATION FOR THE YEAR 2010

\begin{tabular}{|c|c|c|c|c|c|c|}
\hline \multicolumn{3}{|c|}{ Kruse Model } & \multicolumn{3}{c|}{ Kim Model } \\
\hline & $830 \mathrm{~nm}$ & $1550 \mathrm{~nm}$ & $10 \mu \mathrm{m}$ & $830 \mathrm{~nm}$ & $1550 \mathrm{~nm}$ & $10 \mu \mathrm{m}$ \\
\hline Mean & 0.72 & 0.417 & 0.11 & 0.76 & 0.49 & 0.27 \\
\hline Median & 0.34 & 0.151 & 0.01 & 0.34 & 0.15 & 0.01 \\
\hline Mode & 0.09 & 0.03 & 0 & 0.09 & 0.03 & 0 \\
\hline Standard Deviation & 3.18 & 2.54 & 1.32 & 3.66 & 3.63 & 3.59 \\
\hline Range & 117.3 & 99.17 & 59.9 & 131.2 & 131.2 & 131.3 \\
\hline
\end{tabular}

TABLE 4. DESCRIPTIVE STATISTICS OF ESTIMATED OPTICAL ATTENUATION FOR THE YEAR 2011

\begin{tabular}{|c|c|c|c|c|c|c|}
\hline \multicolumn{4}{|c|}{ Kruse Model } & \multicolumn{3}{c|}{ Kim Model } \\
\hline & $830 \mathrm{~nm}$ & $1550 \mathrm{~nm}$ & $10 \mu \mathrm{m}$ & $830 \mathrm{~nm}$ & $1550 \mathrm{~nm}$ & $10 \mu \mathrm{m}$ \\
\hline Mean & 0.73 & 0.41 & 0.11 & 0.769 & 0.49 & 0.27 \\
\hline Median & 0.34 & 0.15 & 0.01 & 0.34 & 0.15 & 0.01 \\
\hline Mode & 0.09 & 0.03 & 0 & 0.09 & 0.03 & 0 \\
\hline Standard Deviation & 3.18 & 2.54 & 1.34 & 3.66 & 3.63 & 3.59 \\
\hline Range & 117.38 & 99.17 & 59.9 & 131.2 & 131.2 & 131.31 \\
\hline
\end{tabular}

TABLE 5. DESCRIPTIVE STATISTICS OF ESTIMATED OPTICAL ATTENUATION FOR THE YEAR2012

\begin{tabular}{|c|c|c|c|c|c|c|}
\hline \multicolumn{4}{|c|}{ Kruse Model } & \multicolumn{3}{c|}{ Kim Model } \\
\hline & $830 \mathrm{~nm}$ & $1550 \mathrm{~nm}$ & $10 \mu \mathrm{m}$ & $830 \mathrm{~nm}$ & $1550 \mathrm{~nm}$ & $10 \mu \mathrm{m}$ \\
\hline Mean & 0.53 & 0.27 & 0.05 & 0.55 & 0.31 & 0.12 \\
\hline Median & 0.37 & 0.16 & 0.01 & 0.37 & 0.16 & 0.01 \\
\hline Mode & 0.34 & 0.15 & 0.01 & 0.34 & 0.15 & 0.01 \\
\hline Standard Deviation & 1.94 & 1.53 & 0.79 & 2.23 & 2.19 & 2.14 \\
\hline Range & 89.87 & 74.8 & 43.19 & 101.47 & 101.53 & 101.56 \\
\hline
\end{tabular}

TABLE 6. DESCRIPTIVE STATISTICS OF ESTIMATED OPTICAL ATTENUATION OF COMBINE DATA FROM 2009 TO 2012

\begin{tabular}{|c|c|c|c|c|c|c|}
\hline \multicolumn{4}{|c|}{ Kruse Model } & \multicolumn{3}{c|}{ Kim Model } \\
\hline & $830 \mathrm{~nm}$ & $1550 \mathrm{~nm}$ & $10 \mu \mathrm{m}$ & $830 \mathrm{~nm}$ & $1550 \mathrm{~nm}$ & $10 \mu \mathrm{m}$ \\
\hline Mean & 0.59 & 0.34 & 0.15 & 0.57 & 0.30 & 0.06 \\
\hline Median & 0.34 & 0.15 & 0.01 & 0.34 & 0.15 & 0.01 \\
\hline Mode & 0.09 & 0.03 & 0 & 0.09 & 0.03 & 0 \\
\hline Standard Deviation & 2.53 & 2.49 & 2.45 & 2.20 & 1.75 & 0.90 \\
\hline Range & 131.31 & 131.31 & 131.31 & 117.47 & 99.21 & 59.9 \\
\hline
\end{tabular}

Mehran University Research Journal of Engineering \& Technology, Volume 37, No. 2, April, 2018 [p-ISSN: 0254-7821, e-ISSN: 2413-7219] 


\section{CONCLUSION}

In this paper we analyzed the measured visibility data of Islamabad for four years and also presented the estimated optical attenuation from visibility using Kruse and Kim model. It was found from the results that maxim attenuation approaches to $120 \mathrm{~dB} / \mathrm{km}$ while the minimum attenuation remained in the range of $2 \mathrm{~dB} / \mathrm{km}$ for almost $99 \%$ of the time. The results clearly indicate very high availability of FSO link at Islamabad. Moreover it is found that Kruse model give higher value of attenuation for 830 $\mathrm{nm}$ wave length while Kim model gives higher value of specific optical attenuation for $10 \mu \mathrm{m}$ wavelength, which means that $1550 \mathrm{~nm}$ wave length is the optimum choice for optical link.

\section{ACKNOWLEDGEMENT}

The authors are thankful to Dr. Kalim Ullah, Department of Meteorology, COMSATS Institute of Information Technology, Islamabad, for helping in experiment setup and valuable discussion on meteorological situation in Islamabad, Pakistan.

\section{REFERENCES}

Arnon, S., and Kedar, D., "Urban Optical Wireless Communication Networks:TheMain Challenges and Possible Solutions", IEEE Communication, Magazine, Volume 42, No. 5, pp. 2-7, USA, 2004.

[2] Muhammad, S.S., Flecker, B., Leitgeb, E., and Gebhart, M., "Characterization of Fog Attenuation in Terrestrial Free Space Optical Links", Optical Engineering, Volume 46, No. 6, pp. 66001-660010, USA,June, 2007.

Leitgeb, E., Bregenzer, J., Fasser, P., and Gebhart, M., "Free Space Optics Extension to Fiber Networks for the Last Mile", Proceedings IEEE of 15th Annual Meeting of LEOS, Volume 2, pp. 459-460, Scotland, 2002.

[4] Amico, M.D., Leva, A., and Micheli, B., "Free-Space Optics Communication Systems: First Results from a Pilot Field-Trial in the Surrounding Area of Milan, Italy", IEEE Microwave and Wireless Components Letters, Volume 13, No. 8, pp. 305-307, USA, August, 2003.
Willebrand, H., and Ghuman, B., "Fiber Optics without the Fiber", IEEE Spectrum, Volume 38, No. 8, pp. 40-45, USA, August, 2001.

[6] Awan, M.S., "Statistical-Dynamical Channel Modeling of Outdoor Optical Wireless Links", Ph.D. Dissertation, Department of Electrical Engineering \& Information Technology, Graz University of Technology, Graz, Austria, 2010.

[7] Toyoshima, M., "Trends in Laser Communication in Space", Conference Report, Space Japan Review, No. 70, pp. 1-6, Japan, October/November, 2010.

[8] Ansari, I.S., Alouini, M.S., and Cheng, J., "Ergodic Capacity Analysis of Free-Space Optical Links With Nonzero Boresight Pointing Errors", IEEE Transactions on Wireless Communications, Volume 14, No. 8, pp. 4248-4264, USA, August, 2015.

[9] Pavelchek, A., Trissel, R.G., Plante, J.,and Umbrasas, S., "Long Wave Infrared $(10 \mu \mathrm{m})$ Free Space Optical Communication System”, Proceedings of SPIE, FreeSpace Laser Communication and Active Laser Illumination-III, Volume 5160, San Diego, California, USA, 2004.

[10] Soibel, A., Wright, M., Farr, W., Keo, S., Hill, C., Yang, R.Q., and Liu, H. C., "Mid-Infrared Inter Band Cascade Lasers for Free-Space Laser Communication", Proceedings of SPIE 7199, Free-Space Laser Communication Technologies XXI, 71990E,USA, 2009.

[11] Arimoto, Y., "Compact Free-Space Optical Terminal for Multi-Gigabit Signal Transmissions with a SingleMode Fiber", Proceedings SPIE 7199, Free-Space Laser Communication Technologies XXI, [doi:10.1117/ 12.808796], USA, 2009.

[12] Douik, A., Dahrouj, H., Al-Naffouri, T.Y., and Alouini, M.S., "Hybrid Radio/Free-Space Optical Design for Next Generation Backhaul Systems", IEEE Transactions on Communications, Volume 64, No. 6, pp. 2563-2577, USA, 2016.

[13] Nadeem, F., and Leitgeb, E., "Dense Maritime Fog Attenuation Prediction from Measured Visibility Data", Journal of Radio Engineering, Volume 19, No. 2, Czech Republic, June, 2010.

[14] Esmail, M.A., Fathallah, H., and Alouini, M.S., "Outdoor FSO Communications under Fog: Attenuation Modeling and Performance Evaluation", IEEE Photonics Journal, Volume 8, No. 4, pp. 1-22, USA, August, 2016. 
[15] Khan, M.S., Naqvi, M.R., Khan, M.A., Khan, R.D., Wali, R., Latif, M., Ullah, K., and Leitgeb, E., "Optical Attenuation Estimation from Measured Visibility Data in Islamabad, Pakistan", $18^{\text {th }}$ European Conference Network and Optical Communications, and $8^{\text {th }}$ Conference on and Optical Cabling and Infrastructure, pp. 203-208, Graz, Austria, 2013

[16] Kvicera, V., and Grabner, M., "The Wavelength Dependent Model of Extinction in Fog and Haze for Free Space Optical Communication", Optics Express, Volume 19, No. 4, pp. 3379-3381, USA, February, 2011.
[17] Kruse, P.W., McGlauchlin, L.D., and McQuistan, R.B., "Elements of Infrared Technology: Generation, Transmission and Detection”, John Wiley\& Sons, New York, 1962.

[18] Kim, I.I., McArthur, B., and Korevaar, E.J., “Comparison of Laser Beam Propagation at $785 \mathrm{~nm}$ and $1550 \mathrm{~nm}$ in Fog and Haze for Optical Wireless Communications", Proceedings SPIE 4214, Optical Wireless Communications-III, Volume 26, [doi:10.1117/ 12.417512], USA, 2001. 